\title{
Varying whole body vibration amplitude differentially affects tendon and ligament structural and material properties
}

\author{
Benjamin V. Keller ${ }^{a},{ }^{,}, 1$, Matthew L. Davis ${ }^{\mathrm{a}}$, William R. Thompson ${ }^{\mathrm{b}}$, Laurence E. Dahners ${ }^{\mathrm{c}}$, \\ and Paul S. Weinhold ${ }^{\mathrm{a}, \mathrm{c}}$ \\ a Joint Department of Biomedical Engineering, University of North Carolina at Chapel Hill, Chapel \\ Hill, NC 27599, United States \\ b Department of Medicine, University of North Carolina at Chapel Hill, Chapel Hill, NC 27599, \\ United States \\ c Department of Orthopaedics, University of North Carolina at Chapel Hill, Chapel Hill, NC 27599, \\ United States
}

\begin{abstract}
Whole Body Vibration (WBV) is becoming increasingly popular for helping to maintain bone mass and strengthening muscle. Vibration regimens optimized for bone maintenance often operate at hypogravity levels $(<1 \mathrm{G})$ and regimens for muscle strengthening often employ hypergravity $(>1 \mathrm{G})$ vibrations. The effect of vibratory loads on tendon and ligament properties is unclear though excessive vibrations may be injurious. Our objective was to evaluate how tendon gene expression and the mechanical/histological properties of tendon and ligament were affected in response to $\mathrm{WBV}$ in the following groups: no vibration, low vibration ( $0.3 \mathrm{G}$ peak-to-peak), and high vibration ( $2 \mathrm{G}$ peak-to-peak). Rats were vibrated for $20 \mathrm{~min}$ a day, 5 days a week, for 5 weeks. Upon sacrifice, the medial collateral ligament (MCL), patellar tendon (PT), and the Achilles Tendon (AT) were isolated with insertion sites intact. All tissues were tensile tested to determine structural and material properties or used for histology. Patellar tendon was also subjected to quantitative RT-PCR to evaluate expression of anabolic and catabolic genes. No differences in biomechanical data between the control and the low vibration groups were found. There was evidence of significant weakness in the MCL with high vibration, but no significant effect on the PT or AT. Histology of the MCL and PT showed a hypercellular tissue response and some fiber disorganization with high vibration. High vibration caused an increase in collagen expression and a trend for an increase in IGF-1 expression suggesting a potential anabolic response to prevent tendon overuse injury.
\end{abstract}

\footnotetext{
(C) 2013 Elsevier Ltd. All rights reserved.

* Corresponding author. Work address: Orthopaedic Research Labs, 134B Glaxo Building. CB\# 7546, 101A Mason Farm Road, Chapel Hill, NC 27599, United States. Tel.: +1 518810 3999. bkeller86@gmail.com (B.V. Keller)..

1800 Ward Street, Chapel Hill, NC 27516, United States.

Conflict of Interest Statement

All authors (Benjamin V. Keller, Matthew L. Davis, William R. Thompson, Laurence E. Dahners, and Paul S. Weinhold) were fully committed to absolute integrity and remained unbiased throughout the study. None of the authors had any conflicts of interest or carried any commitments that would influence their duties.
} 


\section{Keywords}

Whole body vibration; Acceleration; Tendon; Ligament; Collagen expression

\section{Introduction}

Recently there have been a large number of studies examining the potential therapeutic effects of whole body vibration (WBV). Numerous studies have shown that WBV can be anabolic for bone and muscle. Both high $(>2 \mathrm{G})$ and low $(0.3 \mathrm{G})$ vibratory stimuli have been reported to initiate an increase in bone formation rate, bone density, and subsequently bone strength (Oxlund et al., 2003; Rubin et al., 2001). High and low vibration regimens have also elicited notable increases in muscle cross-sectional area and strength in animals as well as humans (Gilsanz et al., 2006; Roelants et al., 2004; Xie et al., 2008). However, the effects of WBV regimens remain relatively unexplored in tendon and ligament tissues. Past work (Hansson et al., 1988) has subjected rats to $4 \mathrm{~h}$ of high-vibration $(6.1 \mathrm{G}, 81 \mathrm{~Hz})$ for two consecutive days. The stimulus was found to be traumatic for the Achilles tendon. They reported a hypercellularity of large, plump fibroblasts that appeared to be in a prolonged synthesizing state which endured 10 days after vibration trauma. Other studies have investigated the response of rat Achilles tendons to $2 \mathrm{G} \mathrm{WBV}$ and found no effect on biomechanical properties (Legerlotz et al., 2007). However, they applied between 2-7 min of vibration a day which is significantly less than that used in other studies or in clinical applications. Recent studies have found that $20 \mathrm{~min}$ of $0.3 \mathrm{G}$ vibration applied daily increased rat flexor tendon cross-sectional area as well as stiffness (Sandhu et al., 2011). It was suspected that the $41 \%$ increase in stiffness was a result of structural changes, suggested by $32 \%$ increase in cross-sectional area.

The goal of our study was to determine the effects of a low and a high vibration level on tendon gene expression and the biomechanical properties of intact ligaments and tendons. Loading of musculoskeletal tissues has been shown to be anabolic but depending on the loading intensity a loading stimulus could also be understimulating or excessive; resulting in ineffectiveness or overuse injury. Commercially available vibration platforms generally operate between 2-6 Gs but some platforms can generate vibrations as large as $16 \mathrm{Gs}$. We hypothesized that both low vibration $(0.3 \mathrm{G})$ and high vibration $(2 \mathrm{G})$ would strengthen ligament and tendon and that low vibration would be more effective because high vibration may be near the threshold to tissue overloading.

\section{Materials and methods}

\subsection{Experimental setup}

After approval by UNC's Institute of Animal Care and Use Committee, 36 retired-breeder female Sprague-Dawley rats were divided into 3 groups of 12: control group, low vibration ( $0.3 \mathrm{G}$ acceleration peak-to-peak) and high vibration ( $2 \mathrm{G}$ acceleration peak-to-peak). Rats were assigned to groups so that the average rat weight in each group was $330 \mathrm{~g} \pm 72 \mathrm{~g}$. Vibration regimens were applied 20 min a day, 5 days a week, for 5 weeks. Rats were placed in a 4 chamber vibration platform which was coupled with an electromagnetic shaker 
(Model N-300, Agac-Derritron Inc., Alexandria, VA). The shaker received a $30 \mathrm{~Hz}$ amplified sine wave signal which was created by a function generator. An accelerometer (352C65, PCB Piezotronics, Depew, NY) was used to ensure the vibration chambers operated at the proper frequency and amplitude levels. The control rats were placed in chambers in an identical housing unit but did not receive any vibration.

After sacrifice, the rats were reweighed and their hind limbs removed. Three left limbs from each group were designated for histology. In the remaining 27 left limbs, the patellar tendon was removed and stored at $-80^{\circ} \mathrm{C}$ for later evaluation by quantitative real time reverse transcription polymerase chain reaction (RT-PCR) and the remaining knee was stored at $-20^{\circ} \mathrm{C}$ for biomechanical testing of the medial collateral ligament (MCL). All 36 right limbs were stored at $-20^{\circ} \mathrm{C}$ and designated for biomechanical testing of the patellar tendon (PT) and the Achilles tendon (AT). Preparation for biomechanical testing involved the removal of surrounding soft tissue, dissection of the hindfoot with the Achilles tendon, and potting of the femur and tibia in PVC tubes with poly-methyl methacrylate (PMMA) bone cement.

\subsection{Biomechanical test setup}

Prior to biomechanical testing, the cross-sectional areas of the tissues were assessed by one of two methods. For tendons, an area micrometer was used to determine the cross-sectional area while a standard compression pressure of $0.12 \mathrm{MPa}$ was applied to the midsubstance (Butler et al., 1984). For the MCL, an optical method was employed using a Dino-Lite Digital Microscope Pro (BigC, Torrance, CA). The tibia was secured in a vertical drill chuck which could be rotated $360^{\circ}$ and the femur was allowed to suspend freely. Minimum and maximum thickness images were taken $90^{\circ}$ apart at the midsubstance of the MCL. The cross-sectional area was calculated as a rectangle given its ribbon-like geometry

All tissue types were tensile tested with a materials testing system (Instron 8500 Plus, Instron Corporation, Norwood, MA). Tensile loading was applied along the long axis of the tissue in order to generate uniform tissue fiber tensioning. Custom jigs were designed to grip the PVC tubes in the following orientations during testing: $\mathrm{MCL}$ at $45^{\circ}$ knee flexion with femur in-line with actuator and tibia angled at $45^{\circ}$ (Lechner and Dahners, 1991). The PT and AT were tensioned in-line with the potted tibia and calcaneus, respectively. The calcaneus was grasped by a drill chuck during testing. A cryoclamp was used to grip the quadriceps tendon at its insertion to the patella during PT testing and the gastrocnemius/soleus muscletendon units during AT testing. For the tendons, the gage length was measured from the tendon insertion site to the cryoclamp edge. For the MCL, the gage length was calculated from the bone insertion site on the femur to the bone insertion site on the tibia.

All samples were pretensioned and preconditioned before testing to failure. Ligaments (MCL) were pretensioned to $0.5 \mathrm{~N}$ whereas tendons (PT and AT) were pretensioned to $2 \mathrm{~N}$. All tissue types were preconditioned at $2 \%$ strain for 10 cycles. Ligaments and tendons were tensioned to failure at a rate of $0.2 \mathrm{~mm} / \mathrm{s}$ and $0.4 \mathrm{~mm} / \mathrm{s}$, respectively. As the test was being executed, load and actuator displacement data were recorded at $30 \mathrm{~Hz}$. From the loaddisplacement curve several structural parameters were derived: ultimate load, stiffness, displacement to ultimate load, and energy to ultimate load. Individual stiffness values were 
calculated by fitting a linear regression equation to the slope of the load-displacement curves between $20 \%$ and $60 \%$ of the ultimate load. The corresponding material properties were also computed utilizing the cross-sectional area and gage length of the specimens (i.e. energy density=energy to ultimate load/(area $\times$ gauge length); stain at ultimate load=displacement at ultimate load/gauge length).

\subsection{Histological examination}

MCLs and PTs designated for histology were immediately placed in 10\% neutral buffered formalin for $48 \mathrm{~h}$ followed by storage in $70 \%$ ethanol. Prior to paraffin embedding, the tissue was decalcified since the patella remained on the PT samples and the tibial bone-tendon interface on the MCL samples. Longitudinal sections were taken in the sagittal plane for the PT and in the coronal plane for the MCL. Both tissues were stained with H\&E and viewed with an Olympus BX40 Microscope (Olympus America, Center Valley, PA).

The histology slides were assessed for cellularity and collagen organization. Cellularity assessment was conducted by 3 blinded graders using a 40× objective. Each specimen had two sections made, separated by $100 \mu \mathrm{m}$. Five regions per section were evaluated by counting the number of fibroblasts per high powered field.

\subsection{RT-PCR}

RNA was extracted from patellar tendons using the TRIspin method as previously described (Reno et al., 1997) and reverse transcribed using iScript cDNA kit (Biorad, Hercules, CA). Q-PCR was completed using the MyiQ detection system (Biorad). Gene expression was normalized to $18 \mathrm{~S}$ levels. Relative expressions of the following genes were determined: Col1a, IGF-1, BMP-12, VEGF, COX-2, IL-1 $\beta$, FLAP, TNF-a, IL-6, and MMP-13 (Table 1).

\subsection{Bone density}

The third caudal vertebrae of the each rat's tail was scanned axially with an in vivo micro-CT system (eXplore speCZT system, GE Heathcare Inc., Waukesha, WI) at a voxel resolution of $50 \mu \mathrm{m}$. The relative bone density was evaluated by measuring the mean gray level of a 1.5 $\mathrm{mm}$ diameter by $1.5 \mathrm{~mm}$ tall cylindrical region of interest centered in the proximal cancellous bone (1 $\mathrm{mm}$ below endplate).

\subsection{Statistical analysis}

A one-way ANOVA test was used to assess group differences of all biomechanical properties. An alpha level of 0.05 was used to determine significance. If significant, a Student-Newman-Keuls post-hoc test was deployed to determine significance between specific groups.

\section{Results}

No significant differences in the biomechanical data occurred between the control group and the low vibration group in any of the examined tissues. The high vibration ultimate load values for the MCL were $21 \%$ and $25 \%$ weaker ( $P$ 0.044) than no vibration and low 
vibration groups, respectively $1 / 4$ (Table 2$)$. No other differences in structural properties were found between the high vibration and control (Table 2).

Material parameters were not affected by vibration, with the exception of the MCL which had a weakening of material properties in the high vibration groups (Table 3). A near significant trend for a decline in tensile strength and a significant decline in energy density were exhibited for the high vibration group relative to the control (Table 3).

Histological assessment of the MCL and patellar tendon tissues revealed hypercellularity in both of the vibration groups (Table 4). Despite elevated cell counts in the vibration groups, they failed to achieve statistical significance due to the small number of specimens $(n=3 /$ group) dedicated to histology. Furthermore, in the control and low vibration group, the cells were narrow and had spindle-shape geometry (Fig. 1a and b). In the high vibration group, all graders reported round plump fibroblasts (Fig. 1c).

Another important observation made by graders regarded the collagen fiber organization. In the high vibration tissues the collagen fibers were disorganized and unaligned, whereas in the control and low vibration tissues the fibers were well-organized and well-aligned (Fig. 1).

Relative expressions of the genes evaluated by RT-PCR are shown (Fig. 2). High vibration caused a significant increase in Colla $(P<0.05)$ and a trend $(P=0.078)$ for an increase in IGF-1 gene expression with respect to the control group. Low vibration caused a trend for an increase in Col1a expression $(P=0.10)$ and IGF- $1(P=0.078)$ expression compared to control tissues. Low vibration also caused a significant decline in COX-2 $(P<0.05)$ expression compared to control tissues. None of the other genes were significantly affected by vibration.

The relative bone density of the proximal cancellous bone of the 3rd caudal vertebrae was significantly $(P<0.05)$ increased in the high vibration group relative to the control, while the low vibration was not found to differ from the control (high vibration: $846 \pm 79$ and low vibration: $765 \pm 103$, control: $698 \pm 126$; mean \pm SD).

\section{Discussion}

Our data suggests that low magnitude vibration $(0.3 \mathrm{G}$ peak-to-peak) either is ineffective or may simply be below the loading threshold needed to cause an anabolic tissue response. In contrast in the MCL, we found evidence that high-magnitude vibration ( $2 \mathrm{G})$ may cause significant weakening of the tissue as demonstrated by reduced ultimate load and energy density values though the mechanical properties of other tissues were unaffected by high vibration. A possible explanation why the MCL was more responsive to high vibration could be that the loads experienced by the MCL during high vibration are higher than normal physiological conditions whereas they may only be slightly higher for the tendon tissues. Ligaments normally do not experience high loads because they serve as joint stabilizers whereas tendons function to transmit higher muscle loads to bone to create bodily movement. Another explanation for the increased responsiveness of the MCL relative to 
tendons is that the MCL has been shown to be more cellular and has a better blood supply (Amiel et al., 1984).

A number of other studies have found that repetitive mechanical stimuli can increase tendon strength and stiffness through tissue hypertrophy (Couppe et al., 2008; Kongsgaard et al., 2007; Magnusson and Kjaer, 2003; Michna and Hartmann, 1989). In past work (Sandhu et al., 2011), experimental rats exposed to the same vibration regimen as our low vibration group exhibited a $41 \%$ increase in stiffness and a $32 \%$ increase in cross-sectional area of a wrist flexor tendon as compared to control rats. This evidence suggests that low-magnitude WBV could cause tissue hypertrophy. In our study, the PT and MCL data revealed elevated ultimate load, stiffness, and cross-sectional area mean values in the low vibration group compared to the controls, but this failed to reach significance. Possible reasons for the increased responsiveness of the flexor carpi ulnaris (FCU) tendon to low vibration in the previous study (Sandhu et al., 2011) may be related to the proximity of the tendon to the vibration source causing higher transmissibility of the vibration. In addition, the close proximity of the FCU tendon to other digital flexors may cause greater frictional effects with the vibration. Finally, the tibia fracture model present in this past study may have caused a weight shift to the forelimbs and increased circulating growth factors that contributed to the responsiveness of the flexor carpi ulnaris tendon to vibration.

Several high intensity endurance exercise studies have documented a decline in the biomechanical strength of tendon (Sommer, 1987; Soslowsky et al., 2002). One study observed a decrease in ultimate tensile strength of the Achilles tendon despite increases in cross-sectional area and total collagen content after intensive running training in rats (Sommer, 1987). Another overuse study in rat supraspinatus tendons also demonstrated increased cross-sectional area measurements accompanied by decreases in maximum stress and tissue modulus values (Soslowsky et al., 2002). Increased collagen expression was found in the patellar tendon with high vibration suggesting the tissues were attempting to remodel themselves. It is unclear if exposure to higher vibration levels over a longer period of time will induce a remodeling response that leads to weakening or strengthening of the tendon. In addition, the expression of inflammatory mediators associated with tendon overuse (Barbe et al., 2008; Perry et al., 2005; Sun et al., 2008) was not found to be significantly increased with high vibration in the patellar tendon though the increase in expression level of IL1- $\beta$ and FLAP with increased vibration amplitude (Fig. 2) is suggestive that these mediators might become significantly increased at higher vibration amplitudes that have been used for muscle strength training.

Histology of both vibration groups revealed a hypercellular response. Hypercellularity is associated with the proliferation stage of tendon healing, prior to remodeling (Chamberlain et al., 2009). Interestingly, the fibroblast morphology and overall tissue organization between the low vibration and the high vibration groups appeared different. In the low vibration group the fibro-blasts were spindle shaped and resembled control fibroblasts. These spindle-shaped fibroblasts generally aligned themselves in long linear arrays, in greater quantity than the control. The collagen fibers in the low-vibration tissue were also neatly organized like the control tissues. Recorded observations from graders suggested a disorganization of collagen fiber structure in the high vibration group. The high vibration 
group had large plump fibroblasts which appeared to be in a more active state. Early work (Hansson et al., 1988) reported similar changes in tendon fibroblasts and increased IGF-1 immunostaining after exposure to high vibration $(81 \mathrm{~Hz}, 6.1 \mathrm{G})$. These authors believed that the fibroblasts were in a prolonged "synthesizing state" which "may induce chronic damage in the tendons." In our study a trend for increased IGF-1 gene expression was observed in the patellar tendon with high vibration (Fig. 2) and this might be the mechanism of the observed hypercellularity as previous work has shown IGF-1 to stimulate proliferation in tendon (Abrahamsson et al., 1991). The hypercellularity of round plump fibroblasts and unorganized collagen structure seen in the high vibration group of the current study and past tendon vibration work (Hansson et al., 1988) resembles the tendon histology in overuse models (Backman et al., 1990; Cho et al., 2011; Glazebrook et al., 2008; Soslowsky et al., 2002). The low vibration group displayed increased cellularity and a trend for increased IGF-1 expression, but without collagen disorganization. It is presumed this different response compared to the high vibration group may be related to the pattern of increasing levels of inflammatory mediators ( IL1- $\beta$, IL-6, and FLAP) with increasing vibration amplitude. A statistical decrease in COX-2 expression in the low vibration may decrease tissue prostaglandin levels and this may have also contributed to the difference in tissue organization between the low and high vibration groups. In contrast, whole body vibration at lower frequencies $(3 \mathrm{~Hz}$ ) has been found to cause an increase in serum prostaglandin E2 levels after a single exposure period (Adams et al., 2005).

Our study has several limitations. We believe that our sacrifice time point at 5 weeks may not have allowed sufficient time for significant changes in mechanical properties to take place. Short-term exercise protocols have been shown to have little to no effect on tendon properties while longer term regimens have shown significant improvements (Jozsa and Kannus, 1997; Sommer, 1987). Secondly, our cross-sectional area measurements were taken at the midsubstance of the ligament or tendon. Studies have found region-specific hypertrophy near the osteotendinous junction of PTs (Couppe et al., 2008; Kongsgaard et al., 2007) and ATs (Magnusson and Kjaer, 2003) that had experienced long-term exercise. Finally, our analysis of gene expression in the patellar tendon tissue at 5 weeks may have missed genes that were expressed early in response to vibration that subsequently returned to basal levels.

In conclusion, the low vibration stimulus $(0.3 \mathrm{G})$ was found to be insignificantly stimulating for all tissues analyzed. Histology of the high vibration group revealed hypercellularity of plumb fibroblasts as well as disorganized collagen structures. In addition, a significant increase of collagen expression and a trend for an increase in IGF-1 expression was found in the patellar tendon with high vibration thus demonstrating potential anabolic responses to vibration. While the mechanical properties of the MCL were negatively affected by high vibration, the tendon properties were unaffected. Further studies will have to determine if more extended application of the current levels of vibration leads to eventual enhancement of tissue strength or if higher amplitudes and durations leads to an overuse condition with deterioration of tissue strength. 


\section{Acknowledgments}

Supported by the Aileen Stock Research Fund. Thanks to Boyi Dai for help with biomechanical testing. Thanks to Dr. Albert Banes and Flexcell International for their consultation.

\section{References}

Abrahamsson SO, Lundborg G, Lohmander LS. Recombinant human insulin-like growth factor-I stimulates in vitro matrix synthesis and cell proliferation in rabbit flexor tendon. Journal of Orthopaedic Research. 1991; 9:495-502. [PubMed: 2045976]

Adams JA, Bassuk J, Wu D, Grana M, Kurlansky P, Sackner MA. Periodic acceleration: effects on vasoactive, fibrinolytic, and coagulation factors. Journal of Applied Physiology. 2005; 98:10831090. [PubMed: 15501928]

Amiel D, Frank C, Harwood F, Fronek J, Akeson W. Tendons and ligaments: a morphological and biochemical comparison. Journal of Orthopaedic Research. 1984; 1:257-265. [PubMed: 6481509]

Backman C, Boquist L, Friden J, Lorentzon R, Toolanen G. Chronic achilles paratenonitis with tendinosis: an experimental model in the rabbit. Journal of Orthopaedic Research. 1990; 8:541-547. [PubMed: 2355294]

Barbe MF, Elliott MB, Abdelmagid SM, Amin M, Popoff SN, Safadi FF, Barr AE. Serum and tissue cytokines and chemokines increase with repetitive upper extremity tasks. Journal of Orthopaedic Research. 2008; 26:1320-1326. [PubMed: 18464247]

Butler DL, Grood ES, Noyes FR, Zernicke RF, Brackett K. Effects of structure and strain measurement technique on the material properties of young human tendons and fascia. Journal of Biomechanics. 1984; 17:579-596. [PubMed: 6490671]

Chamberlain CS, Crowley E, Vanderby R. The spatio-temporal dynamics of ligament healing. Wound Repair and Regeneration. 2009; 17:206-215. [PubMed: 19320889]

Cho NS, Hwang JH, Lee YT, Chae SW. Tendinosis-like histologic and molecular changes of the Achilles tendon to repetitive stress: a pilot study in rats. Clinical Orthopedics and Related Research. 2011; 469:3172-3180.

Couppe C, Kongsgaard M, Aagaard P, Hansen P, Bojsen-Moller J, Kjaer M, Magnusson SP. Habitual loading results in tendon hypertrophy and increased stiffness of the human patellar tendon. Journal of Applied Physiology. 2008; 105:805-810. [PubMed: 18556433]

Gilsanz V, Wren TA, Sanchez M, Dorey F, Judex S, Rubin C. Low-level, high-frequency mechanical signals enhance musculoskeletal development of young women with low BMD. Journal of Bone and Mineral Research. 2006; 21:1464-1474. [PubMed: 16939405]

Glazebrook MA, Wright JR Jr. Langman M, Stanish WD, Lee JM. Histological analysis of achilles tendons in an overuse rat model. Journal of Orthopaedic Research. 2008; 26:840-846. [PubMed: 18183626]

Hansson HA, Dahlin LB, Lundborg G, Lowenadler B, Paleus S, Skottner A. Transiently increased insulin-like growth factor I immunoreactivity in tendons after vibration trauma. An immunohistochemical study on rats. Scandinavian Journal of Plastic and Reconstructive Surgery and Hand Surgery. 1988; 22:1-6. [PubMed: 3387918]

Jozsa, L.; Kannus, P. Human Tendons: Anatomy, Physiology, and Pathology. Human Kinetics Publishers; Champaign, IL USA: 1997.

Kongsgaard M, Reitelseder S, Pedersen TG, Holm L, Aagaard P, Kjaer M, Magnusson SP. Region specific patellar tendon hypertrophy in humans following resistance training. Acta Physiologica Oxford. 2007; 191:111-121.

Lechner CT, Dahners LE. Healing of the medial collateral ligament in unstable rat knees. The American Journal of Sports Medicine. 1991; 19:508-512. [PubMed: 1962719]

Legerlotz K, Schjerling P, Langberg H, Bruggemann GP, Niehoff A. The effect of running, strength, and vibration strength training on the mechanical, morphological, and biochemical properties of the Achilles tendon in rats. Journal of Applied Physiology. 2007; 102:564-572. [PubMed: 17038489] 
Magnusson SP, Kjaer M. Region-specific differences in Achilles tendon cross-sectional area in runners and non-runners. European Journal of Applied Physiology. 2003; 90:549-553. [PubMed: 12905044]

Michna H, Hartmann G. Adaptation of tendon collagen to exercise. International Orthopedics. 1989; 13:161-165.

Oxlund BS, Ortoft G, Andreassen TT, Oxlund H. Low-intensity, high-frequency vibration appears to prevent the decrease in strength of the femur and tibia associated with ovariectomy of adult rats. Bone. 2003; 32:69-77. [PubMed: 12584038]

Perry SM, McIlhenny SE, Hoffman MC, Soslowsky LJ. Inflammatory and angiogenic mRNA levels are altered in a supraspinatus tendon overuse animal model. Journal of Shoulder and Elbow Surgery. 2005; 14:79S-83S. [PubMed: 15726091]

Reno C, Marchuk L, Sciore P, Frank CB, Hart DA. Rapid isolation of total RNA from small samples of hypocellular, dense connective tissues. Biotechniques. 1997; 22:1082-1086. [PubMed: 9187757]

Roelants M, Delecluse C, Verschueren SM. Whole-body-vibration training increases knee-extension strength and speed of movement in older women. Journal of the American Geriatrics Society. 2004; 52:901-908. [PubMed: 15161453]

Rubin C, Turner AS, Bain S, Mallinckrodt C, McLeod K. Anabolism. Low Mechanical Signals Strengthen Long Bones. Nature. 2001; 412:603-604. [PubMed: 11493908]

Sandhu E, Miles JD, Dahners LE, Keller BV, Weinhold PS. Whole body vibration increases area and stiffness of the flexor carpi ulnaris tendon in the rat. Journal of Biomechanics. 2011; 44:11891191. [PubMed: 21396647]

Sommer HM. The biomechanical and metabolic effects of a running regime on the Achilles tendon in the rat. International Orthopedics. 1987; 11:71-75.

Soslowsky LJ, Thomopoulos S, Esmail A, Flanagan CL, Iannotti JP, Williamson JD 3rd, Carpenter JE. Rotator cuff tendinosis in an animal model: role of extrinsic and overuse factors. Annals of Biomedical Engineering. 2002; 30:1057-1063. [PubMed: 12449766]

Sun HB, Li Y, Fung DT, Majeska RJ, Schaffler MB, Flatow EL. Coordinate regulation of IL-1beta and MMP-13 in rat tendons following subrupture fatigue damage. Clinical Orthopedics and Related Research. 2008; 466:1555-1561.

Xie L, Rubin C, Judex S. Enhancement of the adolescent murine musculoskeletal system using lowlevel mechanical vibrations. Journal of Applied Physiology. 2008; 104:1056-1062. [PubMed: 18258802] 
a

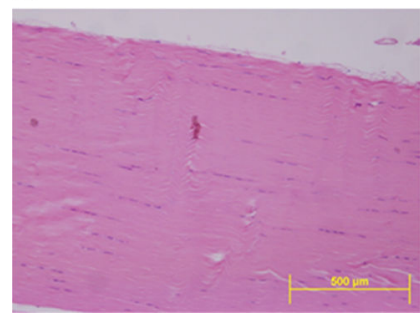

b

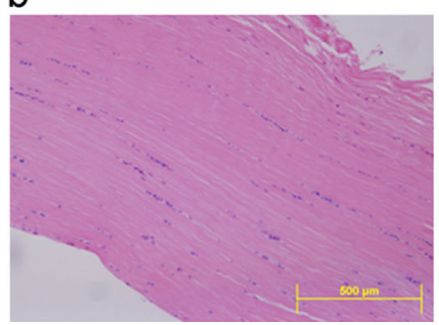

C

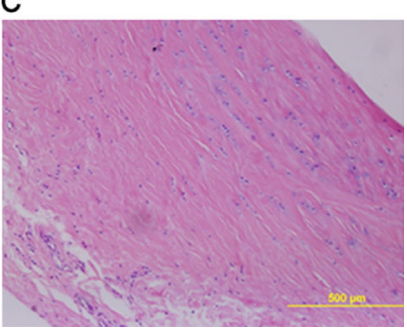

Fig. 1.

H\&E stained MCL samples used for fibroblast counting and collagen fiber organization [100 magnification]. (a) Control MCL, (b) Low Vibration MCL, and (c) High Vibration MCL. 


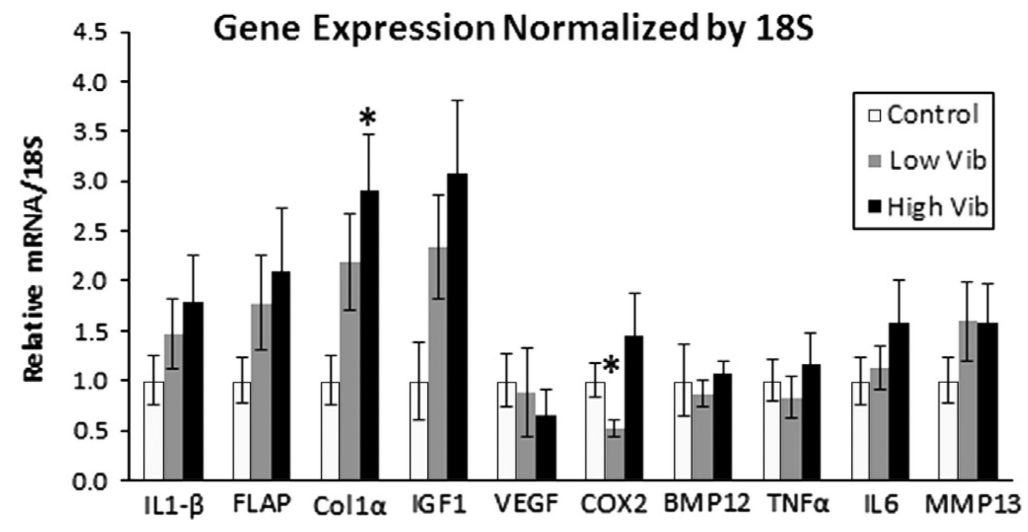

Fig. 2.

qPCR performed on rat patellar tendon after 5 weeks of whole body vibration exposure. The relative gene expressions are normalized by $18 \mathrm{~S}$ gene. $\left.{ }^{*}\right)$ Significant difference $(P<0.05)$ in gene expression from the control group. 


\section{Table 1}

Targeted genes for qPCR of rat patellar tendon $(\mathrm{PT})$. Forward $(\mathrm{F})$ and reverse $(\mathrm{R})$ primers for each gene are displayed.

\begin{tabular}{|c|c|}
\hline Name & Primers \\
\hline \multirow[t]{2}{*}{ IL1-beta } & F: CACCTCTCAAGCAGAGCACAG \\
\hline & R: GGGTTCCATGGTGAAGTCAAC \\
\hline \multirow[t]{2}{*}{ Collalpha1 } & F: GTTCTCGTGGTGCTGCTGGT \\
\hline & R: CTCTTTCTCCTCTCTGACCGGGAA \\
\hline \multirow[t]{2}{*}{ IGF-1 } & F: АTCTCTTCTACCTGGCACTCTGCT \\
\hline & R: GGGGCTGGGACTTCTGAGTCT \\
\hline \multirow[t]{2}{*}{ VEGFA } & F: GGAAAGGGAAAGGGTCAAAAACGA \\
\hline & R: TTCTGTCGACGGTGACGATGGT \\
\hline \multirow[t]{2}{*}{ MMP-13 } & F: CCCCAAAACACCAGAGAAGTGTGA \\
\hline & R: CAGCACTGAGCCTTTTCACCTCT \\
\hline \multirow[t]{2}{*}{$\mathrm{COX}-2$} & F: CGAAGACTACGTGCAACACCTGA \\
\hline & R: ATGGAGGCCTTTGCCACTGCT \\
\hline \multirow[t]{2}{*}{ TNFalpha } & F: AACCAACTGGTGGTACCAGCAGA \\
\hline & R: CCAAAGTAGACCTGCCCGGACT \\
\hline \multirow[t]{2}{*}{ BMP-12 } & F: GCAAGCCACTGCATGTGGACT \\
\hline & R: ACCCTCCCCAGACCTCATGCT \\
\hline \multirow[t]{2}{*}{ IL-6 } & F: ATGTTGTTGACAGCCACTGCCTT \\
\hline & R: TCCAGGTAGAAACGGAACTCCAGA \\
\hline \multirow[t]{2}{*}{ GAPDH } & F: CACCACCATGGAGAAGGC \\
\hline & R: CCATCCACAGTCTTCTGA \\
\hline \multirow[t]{2}{*}{$18 \mathrm{~S}$} & F: ACTGCGAATGGCTCATTAAA \\
\hline & R: CGTCGGCATGTATTAGCTCT \\
\hline \multirow[t]{2}{*}{ FLAP } & F: TCCTGCTCTCTGAAGGTGTC \\
\hline & R: TACAGAAAAACCACCCCAAA \\
\hline
\end{tabular}




\section{Table 2}

Structural properties of Achilles tendon, patellar tendon, and medial collateral ligament (MCL) (mean values \pm standard deviation). Statistical differences between control (*) and low-vibration (\#) [Student-NewmanKeuls].

\begin{tabular}{|c|c|c|c|c|c|c|}
\hline & CSA (mm2) & Gage length $(\mathrm{mm})$ & Ultimate load $(\mathbf{N})$ & Stiffness (N/mm) & $\begin{array}{l}\text { Displacement } \\
\text { at Ultimate } \\
\text { load }(\mathbf{m m})\end{array}$ & $\begin{array}{l}\text { Energy at } \\
\text { Ultimate load } \\
(\mathbf{m J})\end{array}$ \\
\hline \multicolumn{7}{|l|}{ Achilles tendon } \\
\hline No vibration $(n=11)$ & $2.29 \pm 0.59$ & $14.35 \pm 1.76$ & $87.65 \pm 14.20$ & $82.37 \pm 14.56$ & $1.43 \pm 0.21$ & $64.57 \pm 16.34$ \\
\hline Low vibration $(n=12)$ & $2.32 \pm 0.39$ & $14.12 \pm 1.14$ & $87.23 \pm 13.27$ & $84.55 \pm 29.65$ & $1.53 \pm 0.61$ & $66.89 \pm 28.28$ \\
\hline $\begin{array}{l}\text { High Vibration }(n= \\
12)\end{array}$ & $2.25 \pm 0.63$ & $14.6 \pm 1.60$ & $80.99 \pm 16.85$ & $84.00 \pm 16.88$ & $1.89 \pm 0.24$ & $50.04 \pm 19.83$ \\
\hline$P$-value & 0.960 & 0.749 & 0.495 & 0.968 & 0.140 & 0.161 \\
\hline \multicolumn{7}{|l|}{ Patellar tendon } \\
\hline No vibration $(n=10)$ & $2.26 \pm 0.32$ & $9.32 \pm 1.00$ & $82.37 \pm 12.34$ & $87.93 \pm 17.67$ & $1.05 \pm 0.37$ & $49.88 \pm 21.30$ \\
\hline Low vibration $(n=12)$ & $2.34 \pm 0.27$ & $9.24 \pm 0.59$ & $86.17 \pm 13.20$ & $101.91 \pm 20.45$ & $1.07 \pm 0.50$ & $51.17 \pm 20.73$ \\
\hline $\begin{array}{l}\text { High vibration }(n= \\
12)\end{array}$ & $2.12 \pm 0.25$ & $9.04 \pm 0.90$ & $81.21 \pm 15.75$ & $83.96 \pm 22.29$ & $1.05 \pm 0.30$ & $47.77 \pm 16.12$ \\
\hline$P$-value & 0.160 & 0.727 & 0.666 & 0.095 & 0.994 & 0.911 \\
\hline \multicolumn{7}{|l|}{ MCL } \\
\hline No vibration $(n=9)$ & $0.63 \pm 0.16$ & $9.12 \pm 1.63$ & $32.83 \pm 6.25$ & $27.53 \pm 4.00$ & $1.42 \pm 0.32$ & $6.66 \pm 2.45$ \\
\hline Low vibration $(n=7)$ & $0.77 \pm 0.25$ & $9.60 \pm 1.02$ & $34.60 \pm 5.39$ & $31.22 \pm 8.02$ & $1.44 \pm 0.63$ & $6.64 \pm 2.72$ \\
\hline High vibration $(n=7)$ & $0.77 \pm 0.29$ & $9.16 \pm 1.53$ & $26.03 \pm 7.20^{*}, \#$ & $25.26 \pm 7.00$ & $1.45 \pm 1.05$ & $4.94 \pm 2.59$ \\
\hline$P$-value & 0.386 & 0.780 & 0.044 & 0.232 & 0.996 & 0.360 \\
\hline
\end{tabular}




\section{Table 3}

Material properties of Achilles tendon, patellar tendon, and medial collateral ligament (MCL) (mean values \pm standard deviation). Statistical differences between control (*) and low-vibration (\#) [Student-NewmanKeuls].

\begin{tabular}{llll}
\hline & Tensile strength $(\mathbf{M P a})$ & Energy density $\left(\mathbf{m J} / \mathbf{m m}^{\mathbf{3}}\right)$ & Elastic modulus $(\mathbf{M P a})$ \\
\hline Achilles tendon & & \\
No vibration $(n=11)$ & $40.00 \pm 9.60$ & $2.08 \pm 0.64$ & $537.18 \pm 141.34$ \\
$\quad$ Low vibration $(n=12)$ & $39.16 \pm 11.84$ & $2.13 \pm 1.42$ & $568.65 \pm 113.03$ \\
$\quad$ High vibration $(n=12)$ & $37.97 \pm 11.85$ & $1.67 \pm 0.88$ & $547.685 \pm 123.92$ \\
$P$-value & 0.909 & 0.542 & 0.827 \\
Patellar tendon & & & $360.24 \pm 126.45$ \\
No vibration $(n=11)$ & $36.77 \pm 5.59$ & $2.37 \pm 0.86$ & $358.33 \pm 106.27$ \\
Low vibration $(n=12)$ & $36.95 \pm 5.32$ & $2.37 \pm 0.90$ & $349.11 \pm 99.79$ \\
High vibration $(n=12)$ & $38.5 \pm 6.90$ & $2.60 \pm 1.16$ & 0.967 \\
$P$-value & 0.749 & 0.812 & \\
MCL & & & $368.96 \pm 144.43$ \\
No vibration $(n=11)$ & $56.39 \pm 20.61$ & $1.29 \pm 0.59$ & $379.03 \pm 208.73$ \\
Low vibration $(n=12)$ & $47.88 \pm 13.04$ & $0.97 \pm 0.49$ & $297.53 \pm 92.55$ \\
High vibration $(n=12)$ & $36.14 \pm 11.03$ & $0.568 \pm 0.30 *$ & 0.563 \\
$P$-value & 0.065 & $\mathbf{0 . 0 4 3}$ & \\
\hline
\end{tabular}




\section{Table 4}

Fibroblast cell counts from 3 independent graders observing the same field of view (mean values \pm standard deviation). Patellar tendon (PT) shows the mean fibroblast counts for each experimental group, $P=0.321$. Medial collateral ligament (MCL) shows the mean fibroblast counts for each experimental group, $P=0.562$.

\begin{tabular}{lll}
\hline $\begin{array}{l}\text { Average cell count } \pm \text { S.D. } \\
\text { PT }\end{array}$ & MCL \\
\hline $68.4 \pm 3.78$ & Control & $127.8 \pm 21.8$ \\
$92.5 \pm 30.1$ & Low vibration & $153.8 \pm 29.9$ \\
$86.3 \pm 9.98$ & High vibration & $163.7 \pm 59.3$ \\
\hline
\end{tabular}

